\title{
TEXTOS QUE VUELAN: PRODUCCIÓN Y \\ TRAYECTORIAS DE REPORTES ESCRITOS SOBRE LA MIGRACIÓN DE LA MARIPOSA MONARCA'
}

\author{
FLYING TEXTS: PRODUCTION AND \\ TRAJECTORIES OF REPORTS WRITTEN ABOUT THE \\ MIGRATION OF THE MONARCH BUTTERFLY
}

\section{Roberto Méndez-Arreola* Judith Kalman ${ }^{\star \star}$}

\section{RESUMEN}

Los registros y reportes escritos de participantes en programas de ciencia ciudadana han sido valorados a partir de criterios de confiabilidad y validez científica que a menudo invalidan la naturaleza contextual de su escritura. Desde una perspectiva etnográfica basada en los Nuevos Estudios de Cultura Escrita analizamos los procesos de producción y las trayectorias textuales de reportes de dos ciudadanos en un programa de ciencia ciudadana que monitorea la migración de la mariposa monarca en México poniendo atención a la forma como los participantes elaboran sus textos, los recursos materiales y lingüísticos a los que tienen acceso, la manera como están construidos sus escritos, así como la concepción de los autores sobre su elaboración. Reconstruimos la trayectoria de cada texto siguiendo los escritos desde su producción, las actividades sociales que los autores realizan con estos materiales, la forma como se movilizan y modifican de un contexto a otro, los actores involucrados en estos procesos y los significados alrededor de su producción y trayectoria. A través de tres categorías (textos ideales, textos puente y textos globales) mostramos que en su producción y trayectoria textual está muy presente un Discurso normativo (Gee, 2007) sobre lo que es la investigación y el conocimiento científico, y que en consecuncia impacta en la forma de escribir sobre la migración de la mariposa monarca.

1. Los autores agradecemos a todos los participantes del PM quienes nos ofrecieron su conocimiento y experiencia, en particular a su coordinadora RT a quien dedicamos este artículo. Para la realización de este trabajo el primer autor agradece la beca CONACYT para cursar sus estudios de doctorado.

* Doctor en Ciencias en la Especialidad de Investigaciones Educativas. DIE-Cinvestav. Investigador participante del Laboratorio de Educación, Tecnología y Sociedad. Departamento de Investigaciones Educativas. Centro de Investigación y Estudios Avanzados del Instituto Politécnico Nacional, México. Ciudad de México.robcmendez@gmail.com

Orcid: https://orcid.org/0000-0003-1878-2832

** Ph.D en Educación. Universidad de California en Berkeley.

Investigadora titular del Departamento de Investigaciones Educativas. Centro de Investigación y Estudios Avanzados del Instituto Politécnico Nacional, México. Ciudad de México. judymx. docs@gmail.com Orcid: https://orcid.org/0000-0002-0930-5121 
Palabras clave: ciencia ciudadana; culturas escritas; trayectorias textuales; lenguaje científico; mariposa monarca; estudios culturales de la ciencia.

\section{ABSTRACT}

For the most part, the scientific and research community assesses the texts written by participants in citizen science programs on the criteria of reliability and scientific validity, often invalidating the contextual nature of their writing. Using an ethnographic perspective and guidelines of New Literacy Studies, we analyze the production processes and textual trajectories of reports written by two contributors in a citizen science program that monitors the migration of the monarch butterfly in Mexico. We pay attention to the ways they produce their texts, the material and linguistic resources they use, the way they construct their writings, and their ideas about the production of written documents. We reconstruct the trajectory of each text by following them through their production process, their place in the social activities that the authors participate in when creating them, the way the writers transport and modify their writing from one context to another. Through the categories of ideal texts, bridge texts, and global texts, we show that the normative speech of research and scientific knowledge plays a vital role in their production and trajectory (Gee, 2007) and that consequently impacts how participants write about the migration of the monarch butterfly.

Keywords: citizen science; scientific writing; written text; text trajectories.

\section{INTRODUCCIÓN}

Recientemente se ha popularizado la participación de ciudadanos en la investigación científica como voluntarios en diversas tareas. Algunos ejemplos son citados por Xue (2014) y Dickinson et al. (2012) quienes documentaron cómo personas de diversos perfiles, entre ellos estudiantes, profesionistas, pescadores, agricultores y vecinos de áreas urbanas y rurales, así como adultos retirados se involucran en actividades como la escritura de reportes de campo, la clasificación de información documental y el manejo de bases de datos, tareas que en conjunto han sido denominadas como ciencia ciudadana (DEVICTOR, WHITTAKER, \& BELTRAME, 2010; DICKINSON, ZUCKERBERG, \& BONTER, 2010).

En general, los programas de ciencia ciudadana tienen como objetivo generar y analizar grandes cantidades de datos que frecuentemente no pueden realizar los equipos de científicos profesionales por los costos económicos o el esfuerzo humano que implican (OBERHAUSER \& PRYSBY, 2008; OBERHAUSER ET AL., 2015). Si bien, en la literatura se reconoce que hablar de ciencia ciudadana representa un conjunto muy diverso de prácticas, el modelo más común es aquel en el que los ciudadanos se suman a una organización gubernamental o académica para aportar su tiempo y habilidades (y en ocasiones equipo su técnico) con la finalidad 
de generar información de interés para estas instituciones (CATLIN-GROVES, 2012; EITZEL ET AL., 2017).

En particular, la investigación ecológica y las ciencias ambientales se han beneficiado del trabajo de voluntarios comprometidos con la realización de observaciones y registros en proyectos de amplia escala geográfica y temporal tales como la documentación de migraciones de grandes mamíferos; el tiempo ambiental (clima) y la precipitación pluvial, así como migraciones de aves, por citar algunos ejemplos (BONNEY et al., 2009).

En estos proyectos la participación de los ciudadanos ha recibido amplia atención de los científicos profesionales e instituciones gubernamentales pues se ha demostrado su potencial en la producción de información y datos científicos. Por ejemplo, Oberhausser y colaboradores encontraron que el trabajo de voluntarios en programas de ciencia ciudadana sobre mariposas representó un total de 35, 670 horas, una cifra que difícilmente podría ser alcanzada por el trabajo individual de investigadores (OBERHAUSER \& PRYSBY, 2008). Otro ejemplo es el programa FeederWatch del laboratorio de ornitología de la Universidad de Cornell en Estados Unidos que logró estimar el impacto de enfermedades infeccionsas en aves a partir de información proporcionada por cientos de observadores (KOBORI, DICKINSON, WASHITANI, \& TATSUYA, 2016).

Sin embargo, hay quienes afirman que el alcance y potencial de esta práctica está limitada por el nivel de confiabilidad y precisión de los reportes elaborados por los voluntarios o científicos ciudadanos (KOSMALA, WIGGINS, SWANSON, \& SIMMONS, 2016). Si bien, no existe evidencia sólida respecto a la diferencia en calidad y confiabilidad entre reportes elaborados por profesionales y ciudadanos sin formación científica (ACEVES-BUENO et al., 2017) en la literatura este tema se ha presentado como un reto para los proyectos de ciencia ciudadana (WIGGINS et al., 2013; WIGGINS, NEWMAN, STEVENSON, \& CROWSTONS, 2011), e incluso ha llevado a algunos investigadores a manifestar su escepticismo a considerar con seriedad los reportes ciudadanos (KOSMALA et al., 2016; RATNIEKS et al., 2016).

Por ejemplo, hay señalamientos sobre la escritura de los científicos ciudadanos en términos deficitarios ya que se sugiere que ellos suelen hacer reportes cargados de anécdotas, relatos tendenciosos y con observaciones fuera del rango esperable cuando lo que se espera de ellos es que produzcan textos objetivos, informativos y estrictamente limitados al reporte de datos precisos. Otros tambien apuntan que cuando se trata de identificación de especies biológicas es común encontrar 
idenficaciones erróneas que provocan interpretaciones desacertadas que invalida sus observaciones (DICKINSON \& BONNEY, 2012; OBERHAUSER, 2012).

Este retrato de los participantes en el que se les atribuye deficiencias y limitaciones para la escritura científica ha llevado al planteamiento de estratégias para salvaguardar los lineamientos de confiabilidad, precisión, validez y estandarización como la capacitación frecuente, la búsqueda e incorporación de voluntarios con experiencia previa en tareas de ciencia ciudadana, así como la validación de reportes y las bases de datos por parte de expertos (FREITAG, MEYER, \& WHITEMAN, 2016).

Para este artículo partimos de planteamientos de los Nuevos Estudios de Cultura Escrita (NLS, por sus siglas en inglés) acerca de la naturaleza contextual de la escritura y el análisis etnográfico de las prácticas de escritura locales. Estas incluyen tanto las relaciones sociales en las que se sustenta la producción de textos, las concepciones y valoraciones sociales sobre la producción textual, así como el papel que juega la posición social de los escritores y el acceso a recursos discursivos y linguísticos para que su escritura sea considerada como válida por otros lectores (BLOMMAERT, 2013b; STREET, 2003).

Junto con Dikinson y colaboradores (2010) señalamos también que el potencial de los científicos ciudadanos para producir datos científicos es aún pobremente entendido, y como interesados en el estudio de los procesos culturales y discursivos que subyacen a la producción textual proponemos estudiar las prácticas de escritura de un grupo de científicos ciudadanos que documenta la migración de la mariposa monarca en México para una iniciativa que denominamos Programa de Monitoreo de la Mariposa Monarca (PM).

Suscribimos con Street (1984) y otros como Blommaert (2005) y Clark e Ivanic (1997) que la escritura y la producción de lenguaje escrito nunca es una práctica neutra y siempre supone un posicionamiento social y un ejercicio de poder. Esto nos lleva a plantear que las ideas acerca de la confiabilidad y calidad de los reportes que hemos apuntado refiere a un tipo de escritura cercano al estándar científico que representan un régimen normativo que valora la escritura académica pero invalida otras producciones vernáculas (BLOMMAERT, 2005; LILLIS, 2013).

En tal sentido, el objetivo de este artículo es realizar un análisis etnográfico de la producción y circulación de los reportes del PM considerando los textos como una producción situada; poniendo atención a la forma cómo los participantes elaboran sus textos, los recursos materiales y lingüísticos a los que tienen acceso y la manera cómo están construidos sus escritos. Para ello es preciso reconocer no sólo los lineamientos de escritura científica, sino también la concepción de los autores 
sobre la producción de documentos, la forma cómo los textos son transformados para ajustarse a las expectativas de distintos lectores, así como sus propósitos comunicativos para cada público. Implica también ver cómo estos escritos se mueven entre distintintos ámbitos sociales siguiendo su trayectoria desde su producción, analizar que actividades sociales se realizan con estos, cómo son transferidos de un contexto a otro, los actores involucrados en estos procesos y los significados alrededor de su producción y trayectoria complejizando de esta manera la noción de la escritura en la ciencia ciudadana.

\section{DIVERSAS PRÁCTICAS DE ESCRITURA EN LA ACTIVIDAD CIENTÍFICA Y LA CIENCIA CIUDADANA}

Este artículo parte del supuesto acerca de la naturaleza social y comunicativa de la ciencia ciudadana reconociendo el intercambio oral y escrito entre ciudadanos y científicos, y frecuentemente con una audiencia mucho más amplia. La producción de distintos géneros textuales como manuales de capacitación, cartillas informativas, folletos, boletines, blogs, reportes, podcast, así como cartas personales, formularios y solicitudes de información (MÉNDEZ \& KALMAN, 2019) en los proyectos de ciencia ciudadana muestra la importancia de acercarnos a esta actividad desde el estudio de las prácticas de escritura.

En particular, los estudios de prácticas de escritura en actividades científicas han señalado la especificidad de las formas de lenguaje académico practicadas por esta comunidad, un aspecto que ha dado lugar a su caracterización como una comunidad discursiva (BAZERMAN, 1988; LEMKE, 2001). Por ejemplo, para algunos autores como Guiérrez-Rodilla (2005) hablar de lenguaje científico representa una manera económica de referir a un conjunto amplio de prácticas comunicativas que pueden variar con base en las distintas intenciones comunicativas de sus miembros. Para esta autora, hablar de $u n$ lenguaje científico carece de sentido por la diversidad de comunidades profesionales -los físicos, biólogos, antropólogos, por citar algunos-, y la especificidad de sus vocabularios y lenguajes (GEE, 2007).

Los diferentes géneros textuales como el artículo, la reseña, la ponencia presentada en una conferencia académica o el texto de divulgación, el registro escrito de un experimento y una bitácora de datos de campo muestran también la diversidad de formas de escritura y la variedad de propósitos comunicativos y audiencias, por lo que más que un conjunto de características y propiedades específicas siempre presentes en el lenguaje oral o escrito de los científicos, Gutiérrez-Rodilla (2005) reconoce que se trata una tendencia comunicativa hacia 
la precisión, una supuesta objetividad y economía, rasgos que suelen conseguirse a través del uso de vocabulario especializado, el uso de la voz pasiva, la presencia de sustantivos abstractos -o bien, vocabulario científico.

Por otro lado, desde la sociosemiótica, Lemke $(1997,1998)$ ha señalado que la especificidad del lenguaje científico no sólo recae en el uso de cierto vocabulario o algunas formas gramaticales como la voz pasiva, los sustantivos abstractos que sustituyen verbos, o ciertas formas discursivas como la analogía y la argumentación, para este autor, producir lenguaje científico implica conocer la manera como las palabras y otros rasgos textuales se articulan y acomodan para producir significado, es decir, la semántica del lenguaje. Estas formas de organización del texto y de atribución de significado son específicas de cada comunidad discursiva.

Otra manera de aproximarse al estudio del lenguaje en contextos científicos es considerando los géneros textuales o registros. Por ejemplo, Veel (1997), además de confirmar el papel de los textos en la construcción de conocimiento científico en el contexto escolar, elaboró una tipología de los textos más comunes encontrados en aulas de ciencia en Australia. Los géneros de escritura que documentó están relacionados con la función que cumplen estos documentos, por ejemplo encontró instrucciones de procedimiento, informes, explicaciones, justificación, relatos, historietas, entre otros.

Mas recientemente el trabajo de Reid (2019) con un grupo de biólogos de laboratorio mostró los distintos tipos de textos elaborados por este equipo, desde aquellos relacionados con el trabajo cotidiano de laboratorio como notas, bitácoras de datos, manuscritos intermedios; hasta aquellos necesarios para comunicar resultados como textos de divulgación, blogs. Pero sobre todo detalló las transformaciones que estos materiales experimentaron para adaptarlos a diferentes audiencias.

Estos estudios muestran, en primer lugar, la importancia de la escritura en la actividad científica como ha sido ampliamente señalado (BAZERMAN, 2003; LATOUR, 2001; LATOUR \& WOOLGAR, 1986), pero sobre todo, resaltan la diversidad de formas y géneros textuales que son utilizados frecuentemente por las comunidades académicas, donde a menudo, más que encontrar géneros estándar, la tendencia es a la producción de textos híbridos (GEE, 2007). A la vez, nos dejan ver la función que estos diferentes registros cumplen en el contexto social en el que se producen y circulan, así como reflexionar sobre la forma como cada producto escrito forma parte del contexto pues este refleja los significados, las intenciones, los conocimientos y los recursos materiales y simbólicos disponibles y accesibles a los participantes (KALMAN, 2003b). 
Esta visión contextualizada de la escritura remite a la posibilidad de mirar desde otra óptica los planteamientos e ideas sobre la deficiencia y limitaciones de los participantes que se involucran en tareas de escritura en la ciencia ciudadana. En lugar de atribuir deficiencias individuales a la hora de que los participantes elaboran sus reportes nos permite mover el foco hacia la situación y el contexto, sus recursos culturales y propósitos, y entender su producción escrita como una forma legítima de escritura, reconociendo la multiplicidad de significados y la coexistencia de distintas tradiciones discursivas en su producción.

\section{LOS NUEVOS ESTUDIOS DE CULTURA ESCRITA Y LA CIENCIA CIUDADANA}

Desde los llamados NLS, así como la sociolinguística y la antropología de la escritura se ha analizado la producción y circulación de materiales escritos en ámbitos como el trabajo, la calle, la iglesia, el hogar y otras instituciones no oficiales. En general, estos estudios han contribuido a develar una versión más compleja y culturamente más sensible de la escritura y de los procesos de alfabetización (BARTON \& PAPEN, 2010; GEE, 2007; KALMAN, 2003A, 2009; STREET, 2003) enfatizando su naturaleza plural (KALMAN, 2003). Además, desde estas perspectivas se subraya la importancia de las relaciones sociales, las condiciones materiales, los problemas de poder y los arreglos institucionales (BARTON \& HAMILTON, 1998; STREET, 1995) en la escritura y otras prácticas de representación.

En lugar de la versión de la escritura como un conjunto de habilidades individuales que se adquieren exclusivamente en la escuela tales como el manejo del código escrito, la producción de géneros específicos como el ensayo, el reporte, los resúmenes entre otros, los NLS conceptualizan la producción textual como un conjunto de prácticas sociales que son apropiadas y transformadas (ROGOFF, 1997) a partir de la participación de las personas en escenarios sociales particulares donde el lenguaje escrito juega un papel central, así como los vínculos del texto con formas de producción de conocimiento (KALMAN, 1996, 2003c) y como constituyentes de Discursos² (BLOMMAERT, 2005; GEE, 2007).

En un trabajo seminal Street (1984) planteó una distinción entre dos concepciones generales de la escritura que han marcado derroteros en la investigación sobre la producción escrita desde los NLS. Señaló la distinción entre el modelo autónomo e ideológico de la escritura para ilustrar dos concepciones generales

2. El uso de Discurso con D (mayúscula) fue propuesto por Gee (2007) para diferenciar la idea habitual de discurso como sólo una formulación verbal del Discurso como un "modo de acción", un set de recursos para actuar en el mundo y con otras personas, además de un modo de representación. 
y amplias. En la primera, la adquisición y la práctica de la escritura es visualizada como un conjunto de habilidades técnicas de carácter cognitivo y universal, pero sobre todo, independiente de factores culturales y contextuales. Por su parte, el modelo ideológico plantea que la escritura representa un conjunto de prácticas sociales que varían de cultura a cultura y que están mediados por relaciones de poder que establecen la validez de cierto tipo de lenguaje escrito y desdeñan otras formas periféricas de construir significado, una conceptualización que comparte con otras perspectivas sobre el estudio del lenguaje como la sociolinguística y los estudios críticos del discurso, o CDA por sus siglas en inglés (BLOMMAERT, 2008).

Esta distinción permite diferenciar entre el estudio de la escritura como el manejo de convenciones ortográficas y linguísticas, así como la producción de géneros textuales específicos y estandarizados que los individuos resuelven de forma individual, de otro tipo de estudios vinculados a perspectivas etnográficas y culturales que consideran la escritura como un complejo fenómeno social de construcción de significados vinculado al contexto (BARTON, 1994; BLOMMAERT, 2013A; LILLIS, 2013; MÉNDEZ, 2004; TRIMBUR, 2013).

Esta distinción es central para el trabajo que aquí nos ocupa. Una de las principales actividades que realizan los participantes en los programas de ciencia ciudadana es la producción de reportes escritos para remitirlos a instituciones académicas, organizaciones sociales y oficinas gubernamentales que hacen uso de esta información para distintos fines científicos y técnicos. En particular, el PM promueve la participación de ciudadanos que se involucran en la elaboración de reportes escritos de la migración de la mariposa monarca en sus propias localidades, estos reportes son transcritos a una base de datos por personal del programa que a su vez los remite a tomadores de decisiones, gobierno, conservacionistas y científicos.

A la vez, hemos observado que el vínculo entre la producción de datos locales y su uso en ámbitos distintos como el de la planeación de políticas de conservación, el activismo y la investigación científica está mediado por distintas instancias y actores que permiten una transformación de los textos hasta constituirse en datos científicos, y por tanto alejarse de formas más coloquiales y narrativas, que algunos denominan como escrituras vernáculas (BARTON, 1994).

Mientras en la ciencia profesional se ha documentado que la producción de datos empíricos y su transformación a reportes técnicos o artículos no ha sido suficientemente analizada (PONTILLE, 2010), nosotros hemos encontrado que la producción de textos a nivel local, así como sus transformaciones suele ser pasada por alto pues ambos procesos se asumen como habituales en la producción de datos para la ciencia ciudadana. Para analizar la producción local de los textos y 
sus transformaciones hasta que se transforman en un dato científico y la manera que se movilizan a través de distintos ámbitos de actividad social hemos recurrido a la noción de trayectoria textual para referirnos a la historia de los textos -su producción y circulación-, considerando los cambios que los autores hicieron como parte de sus procesos de composición y los significados en torno al manuscrito (KRESS, 2000; LILLIS \& MAYBIN, 2017).

\section{CONTEXTO DE ESTUDIO Y PARTICIPANTES}

Este estudio se realizó con participantes de un programa de ciencia ciudadana en México que promueve el monitoreo de la migración de la mariposa monarca durante los meses de septiembre a noviembre de cada año en México, el PM. Los involucrados son un grupo muy heterogéneo entre los que se encuentran maestros, estudiantes, amas de casa, campesinos, ambientalistas y profesionales.

En particular, en este artículo analizamos la producción escrita de dos participantes que nombramos como Raúl y José. Ambos eran profesionistas (ingeniero agrónomo e ingeniero en comunicaciones, respectivamente) y estaban familiarizados con el manejo de documentos técnicos, el llenado de formatos y la estandarización científica. Raúl era uno de los participantes con más años en el PM y se involucró por invitación directa de los coordinadores del programa; por su parte, José se involucró a partir del 2012 después de tomar un taller de capacitación.

El PM fue lanzado en 1992 y desde entonces, cada año cientos de participantes elaboran y envían a los coordinadores sus reportes de observación en los que escriben el número de mariposas observadas, las condiciones del tiempo ambiental, la fecha de la observación, el nombre del sitio y su referencia geográfica, así como el rumbo de la migración. Al inicio de cada temporada migratoria que comienza en el mes de septiembre, los coordinadores del PM envían a todos los participantes un formulario para la realización de los reportes. Este es usado por algunos participantes quienes lo imprimen para llenarlo a mano; otros capturan los datos en pantalla anexando el documento escrito en el correo electrónico; algunos participantes elaboran una narrativa de la situación en la que hicieron el reporte y utilizan el formulario sólo como modelo para estar seguros que los datos que reportan son los que sugiere este documento.

Cuando conocimos el PM y a sus participantes, la mayor parte de los reportes eran elaborados y enviados a través del correo electrónico. Una vez que estos eran recibidos, los integrantes del equipo de trabajo del programa editaban y recortaban algunas secciones para eliminar datos personales o anecdóticos a fin de preparar los 
textos para ser publicados en el boletín del PM que era compartido también por correo electrónico a todos los participantes y a una audiencia más amplia interesada en seguir el avance de la migración.

Antes del correo electrónico en la década de los noventas, los reportes eran enviados por correo postal. En contraste, los últimos años fue cada vez más frecuente el uso de Facebook y WhatsApp. También se observó una tendencia de los participantes a economizar sus escritos y a ajustar sus reportes a lo datos requeridos por el formulario enviado por los coordinadores del PM al inicio de cada temporada migratoria.

Esta tendencia a elaborar textos "económicos" corresponde con una idea ampliamente difundida y arraigada en otros proyectos de ciencia ciudadana en la que se solicita que los participantes elaboren sus reportes ajustándo su información a lo requerido por un formulario o plantilla. Si bien, reconocemos que la estandarización de los reportes ciudadanos tiene ventajas para la generación de datos de la migración de la mariposa monarca, nos parece importante reconocer que detrás de la elaboración de cada reporte los participantes se involucran en prácticas de escritura más amplias y diversas que resultan invisibles ante los criterios de estandarización, confiabilidad y calidad que desestiman los procesos de producción de escritura local y la naturaleza cultural, sociocultural y semiótica de esta actividad (BLOMMAERT, 2013b; LILLIS, 2013) y la limita a un ejercicio de producción de signos escritos, ingnorando la complejidad y diversidad de la producción de los textos y las diferentes funciones que estos cumplen.

\section{METODOLOGÍA}

Los datos proceden de tres fuentes: el análisis de sus reportes escritos (8 reportes), la transcripción de entrevistas semiestructuradas (3 entrevistas, 140 minutos), así como notas de campo producto de observación participativa durante sus actividades cotidianas y sus monitoreos de la migración de la mariposa monarca por un periodo de ocho meses entre el 2014 y 2015 (6 eventos de observación, 240 minutos).

Para el análisis de sus textos tuvimos acceso a varios de sus reportes elaborados entre el 2012 y 2015. Estos textos representan un retrato de los eventos de escritura que le dieron forma y contenido a cada documento (HALLIDAY \& MATTHIESSEN, 2013; KALMAN, 2003c). Por su parte, Clark e Ivanic (1997) desarrollaron esta noción al conceptualizar los eventos letrados como ocasiones que involucran de alguna manera la presencia de la lectura y/o escritura; para resaltar que 
se trata de ocasiones donde sucede la acción humana, ellos también los denominan como actos de escritura.

El uso del concepto de actos de escritura implica que, en lugar de analizar los reportes de los científicos ciudadanos en su estructura formal, estos representan la huella de las actividades y procesos sociales en los que la escritura está inserta. Es decir, en cada documento se buscó dilucidar las actividades y las prácticas sociales que permitieron su elaboración (BLOMMAERT, 2008; CLARK \& IVANIC, 1997).

Para documentar estos actos de escritura se hizo trabajo de campo con el fin de realizar entrevistas y observaciones sobre el contexto de participación de los científicos ciudadanos. Las entrevistas semiestructuradas tuvieron como objetivo documentar los espacios cotidianos, las actividades laborales, las experiencias escolares y los vínculos sociales de los informantes, a la vez que indagar su percepción acerca de la escritura y el monitoreo, así como revisar con ellos la forma en que elaboraron sus reportes.

Conocer a ambos participantes y visitarlos en sus lugares de trabajo, participar en varias de sus actividades, acompañarlos, observarlos e interactuar con ellos cuando realizaban el monitoreo y conversaban con otras personas sobre el tema de la migración de la mariposa monarca, así como entrevistar a otras personas con las que solían hacer esta actividad nos permitió generar un corpus de notas de campo con el que construímos fichas etnográficas acerca de su participación. Estas fichas fueron revisadas de forma reiterada a fin de identificar tendencias, elementos comunes y diferencias para posteriormente asignar códigos descriptivos y analíticos (HEATH \& STREET, 2008) que daban cuenta de las relaciones sociales, las personas con las que colaboraron, los recursos materiales y linguísticos para la elaboración de sus documentos, los conocimientos y sus intenciones.

Los textos de los participantes y las entrevistas fueron transcritas a fin de reorganizarlos en enunciados individuales siguiendo algunas sugerencias metodológicas para la preparación y análisis de lenguaje escrito. Particularmente, se realizó una organización por líneas que representan unidades de significado; cada una de estas conformada habitualmente por un verbo conjugado y elementos lingüísticos asociados (BLOMMAERT \&JIE, 2010; GEE, 2010). Una vez organizados de esta manera se realizó un trabajo de codificación en el programa Excel siguiendo algunas pautas para su uso como software de análisis de texto propuestas por Kalman y Rendón (2015), donde los códigos que utilizamos -verbos en infinitivopermitían señalar la acción que ocurría en cada línea, así como identificar el actor participante. En una segunda ronda de codificación tratamos de identificar como cada acción codificada con anterioridad formaba parte de actividades más amplias o 
prácticas sociales; aquí, siguiendo a Kalman y Rendón (2015) lo códigos estuvieron conformados por verbos en gerundio que mostraban cómo se trataba de actividades en proceso. La figura 1 muestra una captura de pantalla de cómo se visualiza este proceso en la pantalla.

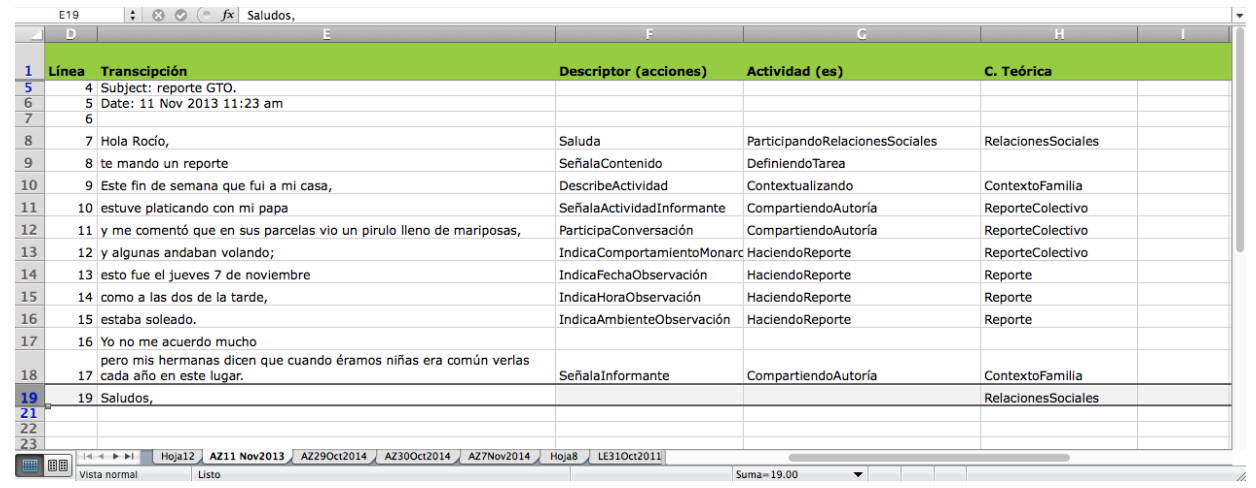

Figura 1. Uso de Exe/para análisis de lenguaje.

En particular para documentar las trayectorias fue necesario recuperar los boletines del PM donde fueron publicados los textos de los participantes y realizar entrevistas a los coordinadores del PM (2 entrevistas, 110 minutos y diversas conversaciones informales) y recuperar las bases de datos del PM.

\section{ANÁLISIS Y RESULTADOS}

En esta sección se presenta el análisis de reportes elaborados por Raúl y José y sus trayectorias textuales. Para ilustrar este análisis y resaltar la trayectoria de los textos hemos construido tres categorías que nos permiten considerar el contenido y características de los textos así como la función que cumplen en su ámbito social. Estas tres categorías corresponden a textos ideales, textos puente y textos globales. Esta clasificación pretende superar la mirada que reduce la valoración de los reportes de los científicos ciudadanos a consideraciones de precisión, validez y calidad; pero sobre todo busca entender y mostrar la diversidad de formas escritas presentes en una actividad de ciencia ciudadana y su importancia. En la tabla 1 se resumen. 
Tabla 1. Descripción de las trayectorias textuales de los reportes elaborados por los participantes del PM. Elaboración propia

\begin{tabular}{|l|l|l|}
\hline $\begin{array}{l}\text { Tipos de texto y } \\
\text { trayectorias textuales }\end{array}$ & Descripción & Autores \\
\hline $\begin{array}{l}\text { Textos ideales } \\
\text { textos para registrar) }\end{array}$ & $\begin{array}{l}\text { Se trata de los manuscritos que los participantes } \\
\text { del PM elaboraron para mantener un registro de } \\
\text { sus observaciones y que utilizan como base para } \\
\text { escribir sus reportes. Son documentos que siguen } \\
\text { lineamientos de escritura científica. }\end{array}$ & $\begin{array}{l}\text { Científicos } \\
\text { ciudadanos }\end{array}$ \\
\hline $\begin{array}{l}\text { Textos puente } \\
\text { textos para reportar) }\end{array}$ & $\begin{array}{l}\text { Se refiere a los reportes de monitoreo como tal } \\
\text { y que eran enviados por correo electrónico a los } \\
\text { encargados del PM. Son textos de naturaleza } \\
\text { híbrida pues incorporan lenguaje científico junto } \\
\text { con otras formas más coloquiales de escritura. }\end{array}$ & Científicos \\
ciudadanos
\end{tabular}

Textos ideales

Raúl. "Lo más real que se pueda"

Para la producción de lo que aquí llamamos textos ideales, se utilizó un formulario de registro. La ocasión que Raúl fue observado y entrevistado en su propio espacio laboral-una oficina gubernamental- señaló que su trabajo le permitía tener acceso a un automovil, una computadora con conexión a internet y datos climáticos que le permitían salir a observar las mariposas, así como componer y enviar su reporte. En esa ocación permitió al primer autor de este artículo (RM) acompañarlo al campo a realizar el monitoreo.

Al regresar a su oficina él señaló en el monitor de su computadora una carpeta donde almacenaba varios documentos relacionados con el monitoreo de la migración de la mariposa monarca. Ahí ubicó el formulario que el PM distribuía entre los participantes (figura 2) con campos predefinidos como datos generales del participante, el nombre de la localidad o sitio, fecha de observación, cantidad de mariposas observadas, su comportamiento y datos ambientales del sitio. Este documento presentaba tambien diez incisos donde se solicitaba seleccionar una opción de una lista de respuestas a manera de preguntas de opción multiple; otros 
incisos requerían la escritura de un texto breve como respuesta. Algunos campos referían al tiempo invertido en cada monitoreo, la cantidad de mariposas observadas, el comportamiento de los insectos, el clima, así como datos ambientales del lugar donde se realizó el monitoreo.
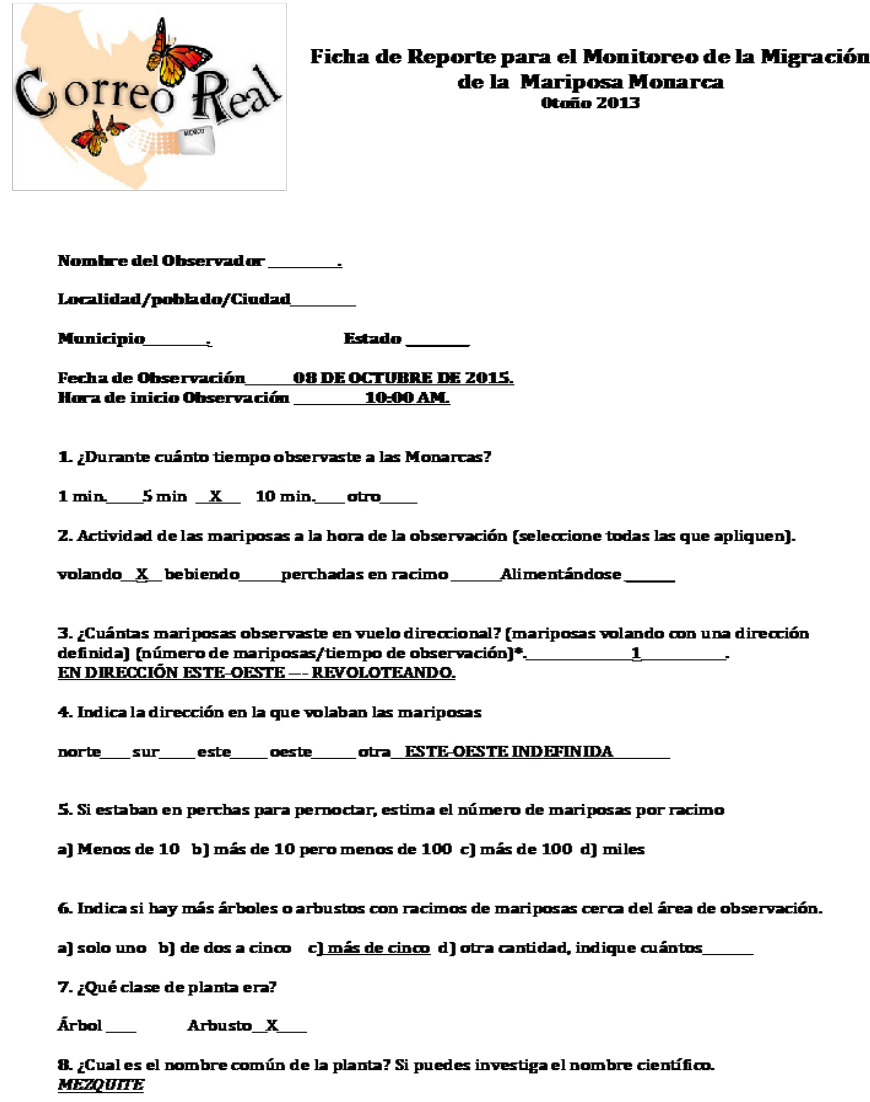

Figura 2. Formulario de registro del PM que llenó Raúl en su computadora. Por consideraciones de anonimato eliminamos el nombre y otros datos que pudieran identificar al autor.

Los primeros incisos los llenó recurriendo únicamente a su memoria, repasando en voz alta datos como [Fecha de observación] y [Hora de inicio de observación]. Mas adelante, los incisos 6, 7 y 8 hacían referencia a las plantas donde las mariposas perchan o descansan [Indica si hay árboles o arbustos con racimos de mariposas cerca del área de observación], [¿Qué clase de planta era?], [¿Cuál es el nombre común de la planta?. Si puedes investiga el nombre cientítico]. En 
particular, en este último inciso, Raúl además de escribir el nombre común de una planta [mezquite] atendió la sugerencia plasmada en el formulario de registrar el nombre científico, lo que hizo buscando en internet y copiando y pegando la información que aparecía en su pantalla (por cuestiones de espacio ya no se incluyó este inciso en la figura 2).

Por su trabajo, este participante tenía la posibilidad de tener acceso a datos climáticos a través del boletín del Servicio Meteorológico Nacional (SMN) por lo que aprovechaba para incluir datos oficiales en su formulario. Para él la posibilidad de tener esta información y hacer consultas por internet formaban parte de elaborar sus reportes "lo más real que se pueda" pues solía asumirse como uno de los primeros ciudadanos en reportar la migración, sabiendo que su reporte circularía ampliamente y sería leído por varios participantes, funcionarios gubernamentales y científicos.

José. Un formulario hecho "a medida"

Cuando conversamos con José, dueño de una pequeña empresa familiar de radiocomunicaciones, sobre la manera cómo llevaba a cabo el monitoreo nos mostró un registro elaborado en una libreta donde también solía hacer sus notas de trabajo (figura 3).

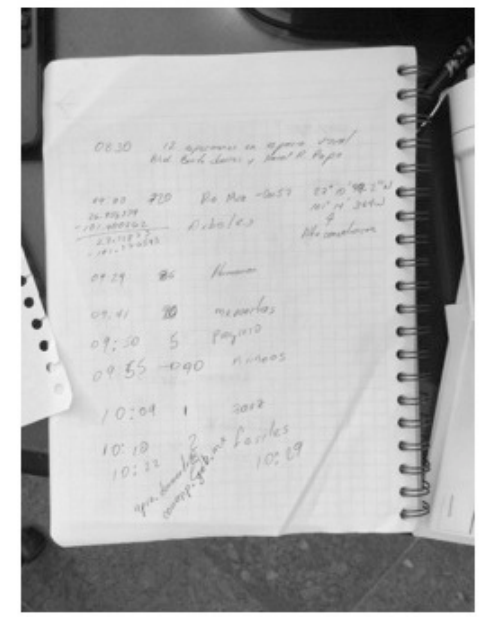

08: 3012 especímenes en el espacio visual Blvd Benito Juarez y Harold R. Pape

7: 20

Río Msa -Car 57

$2710^{\prime} 49.2^{\prime \prime} \mathrm{N}$

$10114^{\prime} 34.4 \mathrm{~W}$

Alta concentración

$\begin{array}{lll}\text { 09:29 } & 86 & \text { Hermanos } \\ \text { 09: } 41 & 20 & \text { Menonitas } \\ \text { 09: } 50 & 5 & \text { Progreso } \\ \text { 09:55 } & 90 & \text { Pirineos } \\ \text { 10:04 } & 1 & \text { Zauz } \\ \text { 10:10 } & 2 & \text { fosiles } \\ \text { 10:22 } & 0 & 10: 29\end{array}$

Figura 3. Hoja de registro en la libreta de José y transcripción

Este participante aprovechaba sus viajes laborales para hacer observaciones y registros de las mariposas ya que las carreteras que recorría eran atravesadas por la ruta migratoria. El registro que mostró estaba escrito a mano y en un cuaderno 
que regularmente solía utilizar para hacer diversos apuntes como lo señaló durante una entrevista:

382 José: venía manejando

383 este es mi conteo,

384 así en mi cuaderno

385 de Monclova a aquí::

386 venía manejando y contando

En la figura 3 transcribimos sus apuntes al lado de la fotografía respetando la redacción y la ortografía de su autor así como la organización de su texto. En cada observación apuntó la hora de su registro de tal manera que la columna en el lado izquierdo de su hoja mostraba la progresión de sus observaciones; a la derecha apuntó el número de ejemplares de mariposas observadas y en seguida el nombre del sitio o alguna referencia geográfica, por ejemplo, el kilómetro de la carretera. En el caso de una observación, la realizada a las 7:20 registró las coordenadas de su observación.

Este registro muestra la manera que este participante adaptó el uso del formulario del PM a las condiciones específicas en las que realizaba su monitoreo. En más de una ocasión durante nuestra entrevista él apuntó que era complicado salir a carretera con el formulario ya que por las diversas ocupaciones laborales y familiares lo único que acostumbraba a cargar a su trabajo era su libreta para hacer apuntes de su jornada laboral. Ello no le impedía hacer observaciones y registros de los datos solicitados por el PM. Para ello adaptó su libreta y la convirtió en una plantilla en la que anotaba datos que eran consistentes con los que aparecían en el formulario (figura 2).

Se puede notar que su registro fue ordenado en la medida que hay una secuencia de lectura que facilita seguir el progreso de sus observaciones: mientras los primeros registros aparecen hasta arriba de esta lista, en las posteriores las va escribiendo en orden descendente estructurando la lectura de sus hojas de notas y dejando en claro la secuencia en que las realizó. Este registro en su libreta le permitió documentar su observación mientras iba por carretera, así como enviarla por correo electrónico en el momento que tuviera tiempo disponible y una mejor conexión a internet.

Tanto el manuscrito de Raúl como el de José representan la continuidad de lo que Lemke (1997) denominó como formas especializadas de uso de lenguaje. $\mathrm{Al}$ completar el formulario y escribir en una libreta varios de los campos señalados en los formularios ambos participantes construyeron una representación científica 
o técnica del fenómeno migratorio que suele ser ampliamente valorada en muchos proyectos de ciencia ciudadana y es reconocida como la forma ideal de realizar registros (KOSMALA et al., 2016; NOV, ARAZY, \& ANDERSON, 2014). En particular la información que se solicita a través de este formulario da continuidad a algunas de las inquietudes y preguntas científicas que han estado vigentes por varias décadas entre los especialistas, entre ellas la ruta migratoria, el origen geográfico de la migración, los sitios de descanso o perchas, así como las tendencias de migración en función de factores ambientales (FLOCKHART et al., 2017).

Sin embargo, como veremos en la siguiente sección, estos textos no son suficientes para participar en el PM por lo que participantes suelen recurrir a otras formas textuales para comunicar sus observaciones, los cuáles hemos denominado textos puente.

\section{Textos Puente}

Desde los estudios literarios, Scarborough (2018) introdujo el concepto de "género puente" (bridge genre, en el texto original) para analizar como durante el siglo XVIII las convenciones textuales de las cartas personales fueron transferidas a nuevos géneros escritos como los periódicos, noveles y biografías, asegurando con ello una mayor aceptación de los lectores y tambien una adecuación de las tecnologías para la producción de los nuevos tipos textuales.

La idea de "género puente" asume que escritores y lectores se mueven y participan alrededor de distintas formas o géneros textuales y a menudo las fronteras entre estos se diluye pues las características propias de un género suelen estar presentes en otro. En esta óptica, proponemos hablar de textos puente como una categoría analítica que nos permite mostrar como los participantes del PM contruyen textos para reportar la migración de la mariposa monarca estableciendo vínculos entre las condiciones locales en las que realizan su observación y la demanda de escritura más técnica. En otras palabras se trata de un texto que retrata condiciones de producción locales, pero apunta y se enlaza a otras audiencias más amplias.

Para ilustrar esta sección utilizaremos un reporte de cada uno los participantes que hemos incluido en este estudio mostrando como además de su registro de la migración de las mariposas monarcas, su participación en el PM require la elaboración de un tipo de texto distinto.

Raúl. "Te envío mi reporte desde ciudad Acuña"

Intencionalmente hemos decidido titular esta sección utilizando una línea del texto de Raúl que elaboró en primera persona para enfatizar como él, a través de 
su manuscrito, se colocó como un participante activo y protagonista en su propio reporte. El uso de la primera persona del singular suele ser desestimada en la práctica científica pues se le asocia a una supuesta falta de objetividad (GEE, 2004; GUIÉRREZ-RODILLA, 2005).

Como vimos en la sección previa, Raúl envió su manuscrito utilizando el formulario del PM. Cuando envió este reporte a los reponsables del programa, además de anexarlo a su e-mail elaboró una narrativa donde incluyó información similar a la del formulario pero incluyendo otros elementos que solemos reconocer como parte de un intercambio epistolar, entre ellos un saludo, una despedida y la firma al final del texto (figura 4).

Entre las líneas 3-8 se puede notar como Raúl incorporó en su mensaje información de varios de los incisos que están presentes en el formulario (figura 2) utilizando una narrativa en primera persona y haciendo uso de un lenguaje coloquial que constrastan con las fórmulas estandarizadas y acotadas que propone el formulario.

1. Buenos días

2. Estimado PM

3. Te envío mi reporte desde la ciudad A

4. te comento que el día de ayer 08 de octubre de 2015

5. observé la primera monarca en el área de la presa

6. el clima estaba caluroso

7. alrededor de 25 grados centígrados

8. con viento suave y mucha humedad

9. La mariposa estaba revoloteando sin dirección fija, más bien como de este a oeste.

10. El día de hoy me daré un recorrido para ver si puedo observar más mariposas.

11. Esperamos el frente frío para que puedan hacerse presentes.

12. Saludos y un fuerte abrazo

13. Raúl

Figura 4. Transcripción de reporte elaborado por Raúl. Por consideraciones de anonimato cambiamos o eliminamos nombres reales así como otros datos que pudieran identificar al autor.

El participante también ofreció información que no aparece en el formulario, por ejemplo en la línea 5 señaló que se trata de su primera observación de la temporada; la línea 10 muestra su intención de seguir monitoreando, y finalmente la línea 11 deja ver su conocimiento sobre la migración y sus conjeturas en base a su experiencia. Se trata de otro tipo de información que los participantes no colocan en el formulario pues este carece de espacio para ello, lo que parecería indicar que el contexto de elaboración, las apreciaciones y el conocimiento de los participantes no es significativo para el PM. Sin embargo es información que da cuenta del 
compromiso del participante, de su conocimiento sobre el fenómeno natural y de cómo la práctica de escritura en la que se involucra está arraigada en aspectos y relaciones sociales.

José. "Aquí le mando también el vínculo a mi Facebook"

En el caso de José encontramos que las observaciones que hacía en su libreta las enviaba a través del correo electrónico. En este reporte que tuvimos acceso a través de su correo electrónico inició con un saludo (figura 5) que representa un elemento muy común en la comunicación oral y escrita (BARTON \& HALL, 1999). Esta presencia constante de saludos, cortesías y atenciones personales en la práctica escrita de la ciencia ciudadana demanda poner atención a las relaciones que se establecen entre los participantes y el papel que estas juegan en la permanencia de los participantes, el tipo de manuscritos que elaboran y los datos que se generan. En particular podemos suponer que los participantes del PM tenían un sólido interés en mantener una relación personal con los coordinadores del programa pues ello implicaba tener acceso a un sector importante de conservacionistas, y de alguna manera relacionarse con ellos y ser parte de los mismos colectivos.

1. PM buenas tardes,

2. no había tenido tiempo de repportar,

3. pero le envío esta imagen de la sierra

4. Mariposa Monarca (Danaus plexippus)

5. $2845^{\prime} 16^{\prime \prime} \mathrm{N}$

6. $10151^{\prime} 28^{\prime \prime} \mathrm{W}$

7. 19 de Agosto de 2012

8. Temp: 9 grados centígrados

9. Viento: total calma

10. Los vaqueros de esa áreas

11.en ese momento me comentaron que no se habían visto gran cosa,

12. pero que cañon es paso de la mariposa,

13. estoy a unos momentos de salir nuevamente para alla,

14. espero poder mandarle un buen reporte esta noche acompañado de iagenes

15.aquí le mando también el vinculo a mi Facebook,

16. donde tengo un álbum público

17. con imágenes de flora y fauna de esta zona

18. saludos

19.José.

Figura 5. Transcripción de reporte elaborado por José en un correo electrónico. Por consideraciones de anonimato cambiamos el nombre y otros datos que pudieran identificar al autor. 
Después de su saludo el texto muestra los datos organizados en una lista de elementos claramente diferenciados (líneas 4-9): el nombre científico de la mariposa monarca, las coordenadas de su observación, la fecha de elaboración del registro y el clima; todos ellos campos que aparecen en el formulario del PM. Luego de los datos de su reporte este participante utilizó varias líneas para hablar de sus informantes. El mantenía un diálogo constante con los trabajadores de campo en la región donde viajaba por trabajo. Ellos solían informarle acerca de la presencia de las mariposas. Las líneas 10 a 12 dejan ver su intercambio con ellos, pero también su participación en la generación de información sobre la migración [10 Los vaqueros de esas áreas 11 en ese momento me comentaron que no se babian visto gran cosa 2 pero que ese cañón es paso de la mariposa].

El siguiente extracto de entrevista muestra, además del contexto social y las relaciones sociales alrededor del manuscrito de José, la naturaleza híbrida de su texto; su reporte no sólo incluye datos técnicos de la migración como el nombre científico, las coordenadas y la temperatura en grados centígrados (líneas 5-8), sino que también incluye información y voces de habitantes de las zona rural que dan como resultado un texto multivocal.

125 José: Le trabajo a los ranchos, 126 son clientes míos, 127 en las localidades

128 y muchos de mis recorridos son por allá, 129 algunos son guardias que están sobre la carretera, 130 y tienen una excelente memoria visual 131 porque es su herramienta para identificar las vacas 132 hay mucho conocimiento para explotar ahí, 133 digo, en términos de el monitoreo

La forma como José cerró su reporte también está impregnada de este interés por mostrar su trabajo y ser reconocido. Entre las líneas 15 a 17 (figura 5) el autor compartió con el PM una serie de fotografías almacenadas en su perfil personal de Facebook [15 aquí le mando también el vinculo a mi Facebook // 16 donde tengo un albun publico// 17 con imágenes de flora y fauna de esta zona], lo que interpretamos como un interés de mostrarse como una persona interesada en el tema de la biodiversidad de la región, así como la manera como su texto y su participación está vinculada a otras actividades y espacios, entre ellos espacios virtuales donde la producción de registros como las imágenes suelen ser ampliamente valoradas. 
Textos globales

La participación de ciudadanos en la investigación sobre la migración de la mariposa monarca ha sido señalada como indispensable para entender el movimiento migratorio de esta especie en un territorio tan extenso (OBERHAUSER ET AL., 2015; URQUHART \& URQUHart, 1976) ya que durante su viaje migratorio cruzan ciudades, campos y áreas naturales en Canadá, Estados Unidos y México.

Si bien, la participación de la población en la colecta y producción de datos ambientales no es un fenómeno nuevo (CONRAD \& HILCHEY, 2011; MILLERRUSHING, PRIMACK, \& BONNEY, 2012; VETTER, 2011) varios autores han señalado que el propósito principal de las actividades de ciencia ciudadana contemporáneas parece estar más relacionado con agendas internacionales que promueven la construcción de bases de datos sobre la biodiversidad con fines de planeación, conservación y uso comercial (TURNHOUT \& BOONMANBERSON, 2011; TURNHOUT, WATERTON, NEVES, \& BUIZER, 2013).

Ello demanda una representación homogénea de la naturaleza a menudo basada en su cuantificación y modelación estadística, es decir recurriendo a un lenguaje y metodologias que puedan ser manejados a través de bases de datos y cartografía digital, asegurando con ello su circulación y uso en diferentes contextos, fenómeno que algunos autores definen como biodiversidad global (TURNHOUT \& BOONMAN-BERSON, 2011). Mientras el concepto de biodiversidad refiere al conjunto de seres vivos en el planeta (LUNA-PLASCENCIA, CASTAÑON \& RAZ-GUZMAN, 2011), hablar de biodiversidad global refiere a los esfuerzos realizados por gobiernos e instituciones académicas por conocer y documentar los seres vivos para conformar bases de datos que permitan cuantificar sus tasas de desaparición y conservación, y estimar su vínculo con bienes como el agua, el aire y la producción de alimentos, mercantilizar los recursos naturales y establecer políticas públicas para su conservación.

Este vínculo entre intereses globales sobre la biodiversidad y programas locales o regionales de ciencia ciudadana se materializa en la demanda de una práctica estandarizada del monitoreo y el registro y documentación de los fenómenos naturales. Se trata de un movimiento de los textos desde un contexto local hasta un ámbito global. A partir de un seguimiento de los reporte de Raúl y José, encontramos evidencia acerca de cómo sus textos originales eran editados y transformados para atender estas demandas que permitían que sus reportes estuvieran disponibles a una audiencia especializada

La figura 6 muestra como el reporte de José fue editado por los responsables PM para ser publicado en el Boletín del PM. Como puede observarse el texto 
fue cortado y reorganizado con dos propósitos: en primer lugar para dar cabida a otros reportes en el boletín pues la extensión original era considerable; en segundo lugar para reservar información propia del intercambio más personal entre José y los coordinadores del programa entre ellos el saludo y detalles sobre la página de facebook del autor del reporte que si aparecen en la versión original (ver figura 5). Finalmente, la información que se publicó en el boletín digital parecíera señalarnos el interés de los reponsables del programa por hacer pública la información predominantemente relacionada con la migración, develando así un interés científico principalmente.

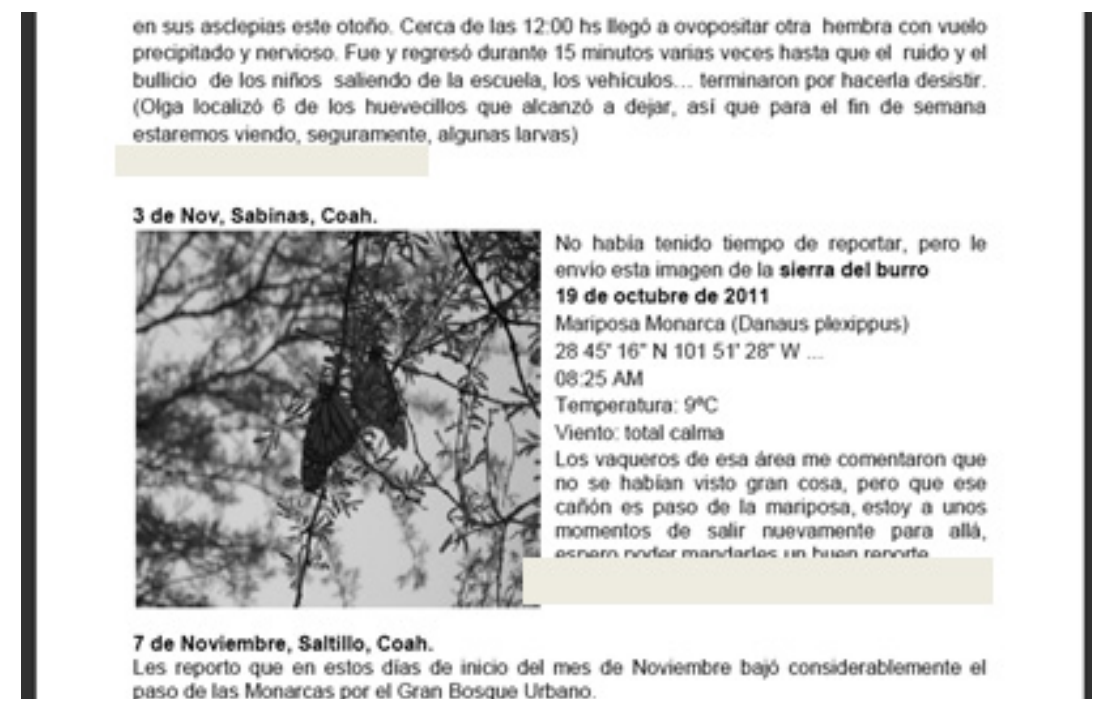

Figura 6. Captura de pantalla de fragmento de Boletín del PM. Se ocultó la identidad real del participante para respetar su anonimato.

Esta tendencia a revelar sólo los datos técnicos del monitoreo se expresa claramente cuando observarmos otro tipo de texto producido por el programa en base a la información recibida de los participantes voluntarios. La figura 7 muestra una captura de pantalla de la base de datos del PM después de aplicar un filtro para la búsqueda del reporte elaborado por José. Esta base de datos se construyó en el programa Excell el cuál fue diseñado para el manejo de datos numéricos. Se trata de una matriz o cuadro de doble entrada que facilita el registro, la organización y el análisis de información a partir de columnas verticales y líneas horizontales.

La imagen de la base de datos muestra como del texto original (figura 5) se transcribieron únicamente los datos técnicos de la migración: estado, municipio, localidad, fecha y hora de observación, número de mariposas y datos ambientales 
del sitio. El lector podrá notar como el archivo de Excell permite mostrar en una sóla pantalla varios reportes del mismo participante, relacionar sus observaciones y incluso empezar a hacer inferencias. Los que estamos involucrados en prácticas académicas sabemos que el uso del programa Excel no se limita a una herramienta para el registro de datos, se trata de un instrumento para la codificación y el análisis de cierto tipo de datos con implicaciones en terminos del tipo de datos que se construyen y que la herramienta puede procesar, a menudo datos cuantitativos.

Los cambios en el texto de José que se han mostrado aquí son realizados por los responsables del PM con el fin de alcanzar una audiencia más especializada como técnicos, científicos y funcionarios gubernamentales interesados en la migración de la mariposa monarca como un fenómeno científico, por lo que su atención se centra en datos específicos como el número de mariposas que migran o las localidades y puntos geográficos ubicados en cartografia. A lo largo de esta trayectoria del escrito de José, los responsables del programa se aseguraron de trabajar el texto para que este cumpliera con los "estándares" requeridos por otra comunidad discusiva más familiarizada y habituada a un lenguaje técnico e interesada en datos "en bruto" y en una representación técnica de la migración de la mariposa monarca.

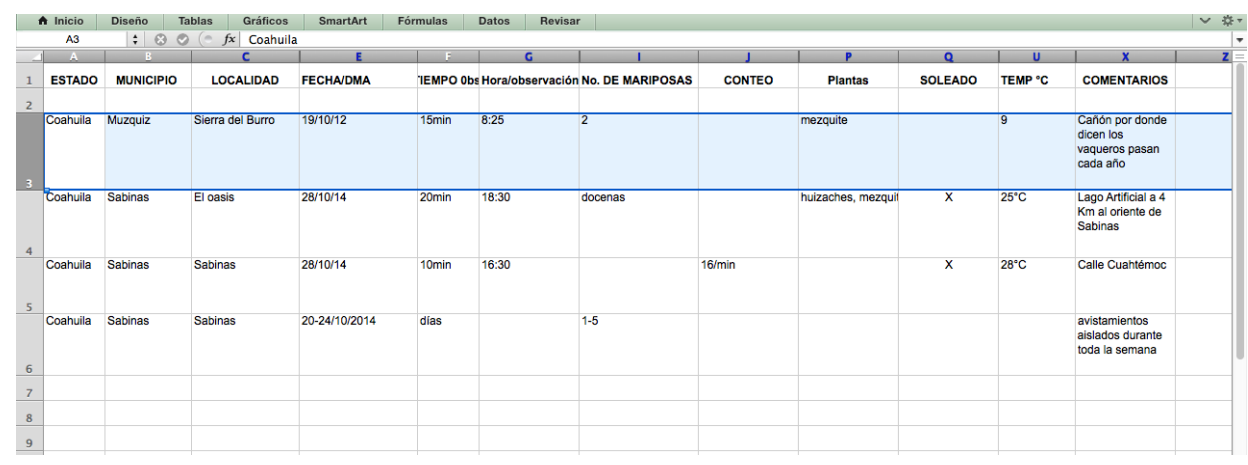

Figura 7. Captura de pantalla de base de datos del PM

Como discutiremos más adelante, el movimiento del texto original hasta la base de datos en Excel va más alla de la edición de un reporte o el movimiento del texto de un soporte físico a otro; se trata de un proceso de producción de datos demandado y validado por una comunidad académica que confía sólo en aquella información que puede ser manipulada en una base de datos y en la pantalla de una computadora.

Cuando analizamos el reporte de nuestro otro participante Raúl (figura 8) encontramos también evidencia de cómo su texto se incorporó a la base de datos siguiendo el mismo formato que el reporte de José. En la base de datos se 
omitió su saludo, así como la información que él ofreció para señalar que se trataba de su primer reporte de la temporada y el compromiso anunciado por seguir al pendiente de la migración de las mariposas. Por el contrario, el Excel sólo dejó lugar a información relacionada exclusivamente con las mariposas y si bien, en una de las columnas se despliega el nombre del participante, este dato no refleja la naturaleza social y contextual del reporte. Aún mas, no muestra el vínculo entre el participante y el fenómeno natural de la migración.

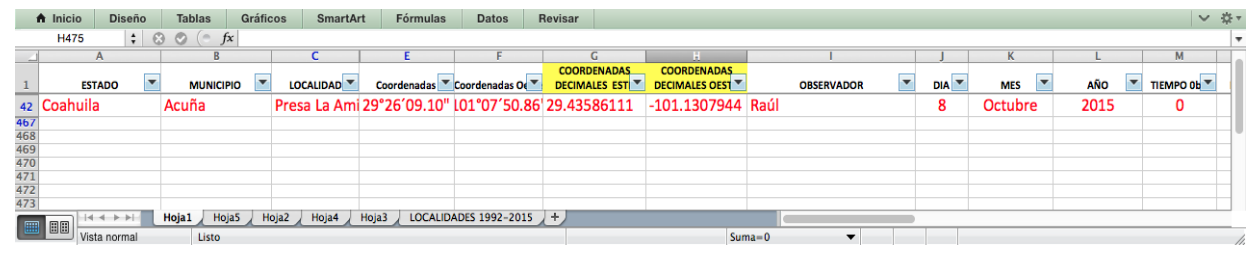

Figura 8. Captura de pantalla de base de datos de PM con reporte de Raúl

Para llegar a esta base de datos, el equipo del PM tomó información de los escritos de los participantes y los transformaron en "datos científicos" que puede a su vez estar sujeto a otras modificaciones, como cuando por ejemplo, estos datos son incorporados a artículo científico, reportes técnicos y mapas. En particular, uno de los principales productos del PM es un mapa de la migración que sintetiza en una imagen las localidades geográficas donde los participantes han registrado avistamientos desde el nicio del programa en la década de los noventas hasta los últimos años.

\section{DISCUSIONES E IMPLICACIONES}

El objetivo de este artículo fue analizar la produccion de reportes escritos de participantes del PM en México como una producción situada a través de una aproximación etnográfica a los textos de dos participantes. Desde la perspectiva de los NLS, se develó además de algunos detalles de la estructura de sus escritos, sus intencionalidades, los recursos lingüísticos y materiales que usaron para su producción, así como sus concepciones sobre la escritura. Nos propusimos también re-construir la trayectoria que siguen estos textos desde su producción hasta el ámbito donde los textos son consumidos por una audiencia especializada de conservacionistas, agentes gubernamentales y académicos.

El análisis centrado en la naturaleza social y contextual de los reportes nos permitió pensar en el papel que estos cumplían en actividades sociales específicas, 
las acciones que las personas hacían con sus escritos (CLARK \& IVANIČ, 1997), y la manera cómo los textos se incorporaban en un flujo de actividades sociales. En otras palabras los textos formaban parte de los colectivos o grupos sociales que se involucraban en su elaboración, circulaban entre las personas que los producían -como textos orales y escrítos-, los leían, los editaban y los consumían. Cuando los reportes eran transferidos a un boletín o a una base de datos se hacía posible su transferencia a otros contextos como laboratorios y oficinas gubernamentales, mientras que la información contextual se iba reduciendo y eliminando.

Las categorías que propusimos en este artículo surgieron del análisis de los materiales escritos producidos por dos participantes del PM pero evocan la producción más amplia de los participantes del programa. Tales categorías no tienen el fin de fragmentar la producción escrita o su circulación, por el contrario buscan mostrar un contínuo entre la producción textual que se realiza a nivel de eventos específicos o actos de escritura y un contexto más amplio de circulación.

Esta mirada está arraigada en la literatura que ha cuestionado la fuerte atención a la producción textual como resultado de variables que se limitan a un contexto local. Kell (2009) por ejemplo en base en Brandt y Clinton (2002) señaló la necesidad de reconocer los textos como parte de prácticas sociales que se concatenan en distintos momentos y ámbitos. Quienes han estudiado el recorrido y movimiento de los textos entre un ámbito social o geográfico y otro (BLOMMAERT, 2008; PONTILLE, 2010) señalan que tales trayectorias textuales están cargadas de consideraciones ideológicas y desigualdades con respecto a la forma como los textos son reconocidos como válidos o no en otros contextos. Como señala Blommaert (2008, p. 6), los textos viajan pero el sistema de uso, evaluación y función en el que originalmente fueron producidos no suele viajar con los textos. En otras palabras, a lo largo de toda la trayectoria textual, está muy presente un Discurso normativo (GEE, 2007) sobre lo que es la investigación y el conocimiento científico, y que en consecuencia impacta en la forma de escribir sobre la migración de la mariposa monarca.

Si bien, en el análisis ofrecimos información para caracterizar cada tipo de texto -texto ideales, textos puente y textos globales- en función de su autoría, el lugar de producción, el lenguje social predominante, su función comunicativa y las expectativas sobre sus posibles audiencias, mostramos tambien que estos tipos textuales se mueven de un contexto a otro y en ese proceso se descontextualizan y adquieren otro estatus - el de dato científico- y a menudo otra autoría (BLOMMAERT, 2013b). 
La presencia del formulario que contiene predefinidas categorías de observación establecía rangos y tipos de respuestas (figura, por lo que a la vez también definía la información válida y la que es descartable. Para algunos autores, el uso de este tipo de formularios asegura la calidad y confiabilidad de los datos colectados por los científicos amateur pues, al sugerir el tipo de información que se requiere y acotar el tipo de respuesta, se reduce la posibilidad que los participantes reporten datos que no son necesarios para el estudio en cuestión, a la vez, se asegura que la elaboración de los reportes corresponda a maneras compatibles con los estudios científicos (KOBORI, DICKINSON, WASHITANI, \& TATSUYA, 2016; MAUZ \& GRANJOU, 2013).

A través de estos formularios, no sólo se sugiere un tipo de respuesta sino también refiere una manera de estructurar la información y el conocimiento a través de un lenguaje particular, vinculado con el tipo de representación de la biodiversidad global. Ello asegura la utilidad de los datos recopilados para ser integrados en bases de datos necesarios para la ciencia profesional (BONNEY et al., 2009; LAWRENCE \& TURNHOUT, 2010).

Estos resultados son similares a los hallazgos de quienes han estudiado procesos de entextualización y/o el movimiento de los textos entre diferentes contextos y han analizado el desplazamiento de los textos en relación a cuestiones de poder y control. Blommaert (2008) mostró como la solicitud de asilo elaboradas por un migrante de Africa a su posible patrocinador belga fue desechada por que esta no se ajustaba al régimen de escritura válido para su patrocinador europeo. Un régimen de escritura refiere a un estándar que rige de forma normativa la forma de producción de lenguaje asociada a ciertos significados, prácticas y Discursos (LILLIS, 2017), opera como un parámetro de evaluación y marginación de formas de escritura que salen de los lineamientos propuestos por tal régimen (TRIMBUR, 2013).

Los textos producidos por los participantes del PM son requisitados a kilometros de distancia de donde fueron generados y claramente se inscriben en un contexto global donde operan prácticas discursivas que tienen sus propios criterios para la interpretación y valoración de los textos (BLOMMAERT, 2013b; TRIMBUR, 2013). A partir de la noción de textos globales pudimos observar que los escritos elaborados por José y Raúl fueron editados y recortados para asegurar su recepción y valoración en un circuito de producción de conocimiento más amplio que el local. La elaboración de lo que aquí llamamos textos globales no es realizado por los autores originales, fue un trabajo asumido por el personal del PM. Una vez que los primeros envían sus textos ellos perdían la posibilidad de incidir en ellos, lo 
cual tambien tiene implicaciones en términos del control que ellos tenían sobre sus textos e información.

Por su parte la elaboración de los textos puente implicó el conocimiento de los participante de la importancia de las relaciones sociales y la necesidad de establecer una comunicación más personal con los coordinadores del PM y con otros posibles lectores. Cuando elaboraron sus textos puente ponían empeño en elaborar un texto híbrido en el que incorporaban los datos de su monitoreo, información proporcionada por otras personas, sus consultas en internet o incluso información oficial como la del SMN y páginas de internet, reflejando de forma más clara las condiciones de producción de sus escritos. En este sentido, sus textos funcionaban como bisagras entre las condiciones locales de producción y el contexto social más amplio y global donde sus textos circulan una vez que se incluyen en el boletín y la base de datos. Así mismo, lejos de ser elaboraciones personales o individuales, resalta el carácter social de sus escritos puesto que era en este lugar donde solían retratar sus vínculos sociales.

Este análisis parece sugerir que al menos, los participantes del PM que incluimos en este estudio pudieron disponer y manejar distintos recursos linguísticos y materiales para producir sus reportes en un texto ideal y un texto puente de forma satisfactoria. Son los protagonistas y diseñadores de sus propios textos. De acuerdo a Kress (2000) el diseño implica un proceso activo y dinámico en el que los autores se enfrentan a la combinación de convenciones arraigadas -que aquí se hacen presentes en la forma de formatos y lenguaje científico-, las preguntas y los temas de investigación de la monarca formuladas por los científicos. En este sentido podemos ver que los participantes del PM son coautores de datos sobre la migración de la monarca. Más que provedores de datos eran participantes activos, con intereses y agendas propias. Sin embargo, ello no fue suficiente para involucrarse en toda la trayectoria de sus textos y ser reconocidos como autores legítimos pues la elaboración de los textos globales recayó en el equipo del PM más familiarizado con las convenciones de escritura científica. En otras palabras, sus recursos son adecuados para producir textos para el PM y la comunidad que se involucra con el programa, pero no para la comunidad científica que demanda datos científicos por lo que la edición de sus textos para ser integrados al boletín y posteriormente a la base de datos fue realizada por el personal del PM.

Esta interpretación tiene distintas implicaciones, en principio nos muestra que, al menos en el PM, la confiabilidad y validez deberían considerarse a la luz de cómo los participantes producen sus reportes reconociendo que son textos significativos desde sus propias condiciones locales de producción, y que la 
elaboración de escritos científicos demanda apropiarse de convenciones de lenguaje de esa comunidad discursiva que mucha veces participantes amateur desconocen. Demandar a los participantes de los proyectos de ciencia ciudadana reportes de suficiente calidad científica sin reconocer sus propias culturas escritas implica exigir el uso mecánico de un régimen de escritura ajeno a sus propias experiencias.

Si nos interesa promover la participación de los ciudadanos en la ciencia ciudadana como un proceso legítimo de aprendizaje a la vez que enfocado a producir datos científicos sólidos deberíamos proponer que los participantes en estas iniciativas se involucraran de manera más activa en comunidades académicas y/o de producción de conocimientos científicos, conocieran y participaran en tareas científicas que implican la producción de distintos géneros textuales, y sobre todo que conocieran el porqué y para qué es necesaria la producción de datos técnicos. Esto puede lograrse a través de favorecer procesos de inmersión y aprendizaje de la práctica científica y el monitoreo ambiental que impliquen el uso gradual del lenguaje científico donde los ciudadanos puedan reconocer que se trata de un código especifico para ciertas tareas y ámbitos sociales, reconociendo también la pluralidad de registros escritos en la práctica científica, su valor y función.

Además, para quienes están interesados en estudiar los procesos de escritura y generación de datos en proyectos de ciencia ciudadana consideramos pertinente proponer un acercamiento etnográfico al contexto social y cultural de los participantes que permita develar sus prácticas de escritura, sus recursos linguísticos, así como sus valoraciones sobre la escritura y su participación en tales proyectos. Estudiar las trayectorias textuales de los reportes de los participantes puede contribuir tambien a reconocer la naturaleza colectiva de la ciencia ciudadana así como los regímenes de escritura naturalizados en esta práctica, un paso necesario para valorar otras culturas escritas y reconocer la pluralidad de las prácticas de escritura en contextos de producción de información ambiental.

\section{REFERENCIAS}

ACEVES-BUENO, E., ADELEYE, A., FERAUD, M., HUANG, Y., TAO, M., YANG, Y., \& ANDERSON, S. (2017). The Accuracy of Citizen Science Data: A Quantitative Review. Bulletin of the Ecological Society of America, 98 (4), 278-290.

BARTON, D. (1994). Literacy. An introduction to the ecology of written language. Oxford: Blackwell.

BARTON, D., \& HALL, N. (1999). Letter Writting as a Social Practice. Amsterdam: John Benjamins Publishing Company. 
BARTON, D., \& HAMILTON, M. (1998). Local literacies: Reading and writing in one community: Routledge.

BARTON, D., \& PAPEN, U. (2010). What Is the Anthropology of Writing? En D. Barton \& U. Papen (Eds.), The Antbropology of Writing. Understanding Textually-Mediated Worlds. Londres: Continuum.

BAZERMAN, C. (1988). Shaping written knowledge: The genre and actitivy of the experimental article in science (Vol. 356). Madison: University of Wisconsin Press.

BAZERMAN, C. (2003). Speech acts, genres, and activity systems: How texts organize activity and people. En: C. Bazerman \& P. Prior (Eds.), What writing does and how it does (pp. 315-346). Mahwah, New Jersey: Routledge.

BLOMMAERT, J. (2005). Discourse: A critical introduction: Cambridge University Press.

BLOMMAERT, J. (2008). Grassroots literacy. Writing, Identity and Voice in Central Africa. New York: Routledge.

BLOMMAERT, J. (2013a). Ethnograpby, superdiversity and linguistic landscapes: Chronicles of complexity (Vol. 18). Bristol, Buffalo y Toronto Multilingual Matters.

BLOMMAERT, J. (2013b). Writing as a sociolinguistic object. Journal of Sociolinguistics, 17(4), 440-459.

BLOMMAERT, J., \& JIE, D. (2010). Ethnographic fieldwork: a beginner's guide. Bristol: Multilingual Matters.

BONNEY, R., COOPER, C., DICKINSON, J., KELliNG, S., PHILliPS, T., ROSENBERG, K., \& SHIRK, J. (2009). Citizen Science: A Developing Tool for Expanding Science Knowledge and Scientific Literacy. BioScience, 59(11), 977-984.

BRANDT, D., \& CLINTON, K. (2002). Limits of the local: Expanding perspectives on literacy as a social practice. Journal of Literacy Research, 34(3), 337-356.

CATLIN-GROVES, C. L. (2012). The citizen science landscape: from volunteers to citizen sensors and beyond. International Journal of Zoology, 2012.

CLARK, R., \& IVANIČ, R. (1997). The politics of writing. Londres y Nueva York: Routledge. 
CONRAD, C. C., \& HILCHEY, K. G. (2011). A review of citizen science and communitybased environmental monitoring: issues and opportunities. Environmental Monitor Assessment, 176(1-4), 273-291.

DEVICTOR, V., WHITTAKER, R. J., \& BELTRAME, C. (2010). Beyond scarcity: citizen science programmes as useful tools for conservation biogeography. Diversity and distributions, 16(3), 354-362.

DICKINSON, J., \& BONNEY, R. (2012). Why Citizen Science? En J. Dickinson \& R. Bonney (Eds.), Citizen Science. Public participation in environmental research (pp. 1-14). Ithaca, NY: Cornell University Press.

DICKINSON, J., ZUCKERBERG, B., \& BONTER, D. (2010). Citizen science as an ecological research tool: challanges and benefits. Annual Review of Ecology, Evolution and Systematics, 41, 149-172.

DICKINSON, J. L., SHIRK, J., BONTER, D., BONNEY, R., CRAIN, R. L., MARTIN, J., ... PURCELL, K. (2012). The current state of citizen science as a tool for ecological research and public engagement. Frontiers in Ecology and the Environment, 10(6), 291-297.

EITZEL, M., CAPPADONNA, J. L., SANTOS-LANG, C., DUERR, R. E., VIRAPONGSE, A., WEST, S. E., . . SFORZI, A. (2017). Citizen science terminology matters: Exploring key terms. Citizen Science: Theory and Practice, 2(1).

FREITAG, A., MEYER, R., \& WHITEMAN, L. (2016). Strategies Employed by Citizen Science Programs to Increase the Credibility of Their Data. Citizen Science: Theory and Practice, 1(2), 1-11.

FLOCKHART, D., BROWER, L. P., RAMIREZ, M. I., HOBSON, K. A., WASSENAAR, L. I., ALTIZER, S., \& NORRIS, D. R. (2017). Regional climate on the breeding grounds predicts variation in the natal origin of monarch butterflies overwintering in Mexico over 38 years. Global change biology, 23(7), 2565-2576.

GEE, J. P. (2004). Language in the science classroom: Academic social languages as the heart of school-based literacy Establishing scientific classroom discourse communities: Multiple voices of teaching and learning research: Lawrence Erlbaum Associates.

GEE, J. P. (2007). Social linguistics and literacies: Ideology in discourses: Routledge.

GEE, J. P. (2010). How to do discourse analysis: A toolkit: Routledge.

GUIÉRREZ-RODILLA, B. (2005). El lenguaje de las ciencias. Madrid: Gredos. 
HALLIDAY, M., \& MATTHIESSEN, C. (2013). Halliday's introduction to functional grammar: Routledge.

HEATH, S. B., \& STREET, B. V. (2008). On Ethnograpby: Approaches to Language and Literacy Research. Language \& Literacy (NCRLL): ERIC.

KALMAN, J. (1996). Joint composition: The collaborative letter writing of a scribe and his client in Mexico. Written Communication, 13(2), 190-220.

KALMAN, J. (2003a). El acceso a la cultura escrita: la participación social y la apropiación de conocimientos en eventos cotidianos. Revista Mexicana de Investigación Educativa, $\operatorname{VIII}(17), 37-66$.

KALMAN, J. (2003b). El acceso a la cultura escrita: la participación social y la apropiación de conocimientos en eventos cotidianos de lectura y escritura. Revista Mexicana de Investigación Educativa, 8(17), 37-66.

KALMAN, J. (2003c). Escribir en la plaza. México, D. F: Fondo de Cultura Económica.

KALMAN, J. (2009). San Antonio iMe urge!. Preguntas sin respuesta acerca de la especificidad de dominio de los géneros textuales y las prácticas leltradas. In J. Kalman \& B. Street (Eds.), Lectura, Escritura y Matemáticas como Prácticas Sociales. México, D. F: CREFAL, Siglo XXI Editores.

KALMAN, J., \& RENDÓN, V. (2015). Uso de la hoja de cálculo para analizar dsatos cualitativos. Magis. Revista Internacional de Investigación en Educación, 9(18).

KELL, K. (2009). Situar las prácticas: nuevos estudios de cultura escrita y estudios etnográficos en Sudáfrica. En J. Kalman \& B. Street (Eds.), Lectura, Escritura y Matemáticas como Prácticas Sociales (pp. 364-386). México: Siglo XXI.

KOBORI, H., DICKINSON, J., WASHITANI, R., \& TATSUYA, A. (2016). Citizen science: a new approach to advance ecology, education and conservation. Ecological research, 31(1), 1-19.

KOSMALA, M., WIGGINS, A., SWANSON, A., \& SIMMONS, B. (2016). Assesing data quality in citizen science. Frontiers in Ecology and the Environment, 14(10), 551-560.

KRESS, G. (2000). Desingn and Transformation. New Theories of Meaning. En B. Cope \& M. Kalantzis (Eds.), Multiliteracies: Literacy Learning and the Desing of Social Futures (pp. 149-157): Routledge. 
LATOUR, B. (2001). La esperanza de Pandora. Ensayos sobre la realidad de los estudios de la ciencia. Barcelona: Gedisa.

LATOUR, B., \& WOOLGAR, S. (1986). Laboratory Life: The Construction of Scientific Facts: Princeton University Press.

LAWRENCE, A., \& TURNHOUT, E. (2010). Personal meaning in the public sphere: The standardisation and rationalisation of biodiversity data in the UK and the Netherlands. Journal of Rural Studies, 26(4), 353-360.

LEMKE, J. (1997). Aprender a bablar ciencia. Lenguaje, aprendizaje y valores. Barcelona: Paidós.

LEMKE, J. (1998). Multiplying meaning. Visual and verbal semiotic in scientific text. En J. Martin \& R. Veel (Eds.), Reading Science. Londres: Routledge.

LEMKE, J. (2001). Articulating communities: Sociocultural perspectives on Science Education. Journal of Research in Science Teaching, 38(3), 296-316.

LILLIS, T. (2013). Sociolinguistics of writing: Edinburgh University Press.

LILLIS, T. (2017). Resistir regímenes de evaluación en el estudio del escribir: hacia un imaginario enriquecido. Signo y Pensamiento, 36(71).

LILLIS, T., \& Maybin, J. (2017). Introduction: The dynamics of textual trajectories in professional and workplace. Text and Talk, 37 (4), 409-414.

LUNA, R., CASTAÑON, A., \& RAZ-GUZMÁN, A. (2011). La biodiversidad en México: su conservación y las colecciones biológicas. Ciencias 101, enero-marzo, 36-43.

MAUZ, I., \& GRANJOU, C. (2013). A new border zone in science. Collaboration and tensions between modelling ecologists and field naturalists. Science as Culture, 22(3), 314-343.

MÉNDEZ, J. M. (2004). El escrito académico: un tejido de textos múltiples. México, D.F. Universidad Pedagógica Nacional.

MÉNDEZ-ARREOLA, R \& KALMAN, J (2019). Lo que escriben los científicos locales. El texto como acción social. Íkala, Revista de Lenguaje y Cultura, 24(1). 271-290.

MILLER-RUSHING, A., PRIMACK, R., \& BONNEY, R. (2012). The history of public participation in ecological research. Frontiers in Ecology and the Environment, 10(6), 285-290. 
NOV, O., ARAZY, O., \& ANDERSON, D. (2014). Scientist@Home: What Drives the Quantity and Quality of Online Citizen Science Participation? PloS one, 9(4), e90375.

OBERHAUSER, K. (2012). Monitoring Monarchs: Citizen Science and a Charismatic Insect. En J. Dickinson \& R. Bonney (Eds.), Citizen Science. Public participation in environmental research (pp. 35-42). Ithaca y Londres: Comstock Publishing Associates.

OBERHAUSER, K., \& PRYSBY, M. D. (2008). Citizen science: creating a research army for conservation. American Entomologist, 54(2), 103-104.

OBERHAUSER, K., RIES, L., ALTIZEL, S., BATALDEN, R., KUDELL-EKSTRUM, GARLAN, M., ... WALTON, D. (2015). Contributions to Monarch Biology and Conservation through Citizen Science: Seventy Years and Counting. En K. Oberhauser, K. Nail, \& Altizer (Eds.), Monarcbs in a changing world: biology and conservation of an iconic butterfly. Ithaca y Londres: Cornell University Press.

PONTILLE, D. (2010). Updating a biomedical database: writing, reading and invisible contribution. En Barton, D y Papen, U. (ed.) (2010). Antbropology of Writing: Understanding Textually-Mediated Worlds, London, Continuum, 47-66.

RATNIEKS, F., SCHRELL, F., SHHEPARD, R., BROWN, E., BRISTOW, O., \& GARBUZOV, M. (2016). Data reliability in citizen science: learning curve and the effects of training method, volunteer background and experience on identification accuracy of insects visiting ivy flowers. Methods in Ecology and Evolution, 7(10), 1226-1235.

REID, G. (2019). Compressing, Expanding, and Attending to Scientific Meaning: Writing the Semiotic Hybrid of Science for Professional and Citizen Scientist. Written Communication, 36(1), 68-98.

ROGOFF, B. (1997). Los tres planos de la actividad sociocultural: apropiación participativa, participación guiada y aprendizaje. En J. Wertsch, P. del Río, \& A. Álvarez (Eds.), La mente sociocultural. Aproximaciones teóricas y aplicadas (pp. 111-128). Madrid: Fundación Infancia y Aprendizaje.

SCARBOROUGH, K. (2018). Writing to the World: Letters and the Origins of Modens Print Genre. Baltimore: Johns Hopkins University Press.

STREET, B. (1984). Literacy in theory and practice. Cambridge: Cambridge University Press.

STREET, B. (1995). Social Literacies. Critical Approaches to Literacy in Development, Etbnograpby and Education. Nueva York: Routledge. 
STREET, B. (2003). What's "new" in New Literacy Studies?. Critical approaches to literacy in theory and practice. Current Issues in Comparative Education, 5(2), 77-91.

TRIMBUR, J. (2013). Grassroots literacy and the written record: Asbestos activism in South Africa. Journal of Sociolinguistics, 17(4), 460-487.

TURNHOUT, E., \& BOONMAN-BERSON, S. (2011). Databases, scaling practices, and the globalization of biodiversity. Ecology and Society, 16(1).

TURNHOUT, E., WATERTON, C., NEVES, K., \& BUIZER, M. (2013). Rethinking biodiversity: from goods and services to "living with". Conservation Letters, 6(3), 154-161.

URQUHART, F. A., \& URQUHART, N. (1976). The overwintering site of the Eastern population of the monarch butterfly (Danaus P. Plexippus: Danaidae) in Southern Mexico. Journal of The Lepidopterists' Society, 30(3), 153-158.

VEEL, R. (1997). Learning how to mean-scientifically speaking: apprenticeship into scientific disourse in the secondary school. En F. Christie \& J. R. Martin (Eds.), Genre and institutions. Social Process in the Workplace and School. Londres: Continuum.

VETTER, J. (2011). Lay Observers, Telegraph Line, and Kansas Weather: The Field Network as a Mode of Knowledge Production. Science in Context, 24(2), 259-280.

WIGGINS, A., BONNEY, R., GRAHAM, E., HENDERSON, S., KELLING, S., LITTAUER, R., ... WELTIZIN, J. (2013). Data Management. Guide for Public Participation in Scientific Research. . Albuquerque, NM: DataONE.

WIGGINS, A., NEWMAN, G., STEVENSON, R., \& CROWSTONS, K. (2011). Mechanisms for data quality and validation in citizen science. Paper presented at the IEEE Seventh International Conference on e-Science Workshops.

XUE, K. (2014). Popular Science. Harvard Magazine, 54-59.

Recebido: 21/10/2019

Aceito: 30/11/2019

Publicado: 28/02/2020 